\title{
ADAR, the carcinogenesis mechanisms of ADAR and related clinical applications
}

\author{
Yue Zhang, Huizhu Qian, Jing Xu, Wen Gao \\ Department of Oncology, The First Affiliated Hospital of Nanjing Medical University, Nanjing 210029, China \\ Contributions: (I) Conception and design: Y Zhang; (II) Administrative support: W Gao; (III) Provision of study materials or patients: Y Zhang; (IV) \\ Collection and assembly of data: Y Zhang; (V) Data analysis and interpretation: Y Zhang; (VI) Manuscript writing: All authors; (VII) Final approval \\ of manuscript: All authors. \\ Correspondence to: Wen Gao; Jing Xu. Department of Oncology, The First Affiliated Hospital of Nanjing Medical University, 300 Guangzhou Road, \\ Nanjing 210029, China. Email: gaowen@jsph.org.cn; xujing7901@jsph.org.cn.
}

\begin{abstract}
Adenosine deaminases acting on RNA (ADARs) catalyze the conversion of adenosine (A) to inosine (I) in double-stranded RNA, which can change the codons after transcription. Abnormal ADAR editing is present in a variety of cancers. However, the study of the biological effects of ADARs in cancer is not very deep. Here, we review current important ADAR-mediated editing events, related carcinogenic mechanisms and applications in clinical medicine. Further exploration in ADARs can provide a new direction for cancer treatment.
\end{abstract}

Keywords: Adenosine deaminases acting on RNA (ADARs); A to I RNA editing; carcinogenic mechanism; clinical utility

Submitted Oct 08, 2019. Accepted for publication Oct 21, 2019.

doi: $10.21037 /$ atm.2019.11.06

View this article at: http://dx.doi.org/10.21037/atm.2019.11.06

\section{Introduction}

Gene mutations have long been the focus of cancer occurrence and development. In recent years, epigenetic mechanisms and their abnormal function are also important in the development of neoplasia (1). RNA editing has been identified for the involvement in cancer (2), the most common type of which is ADAR-mediated RNA editing in higher eukaryotes, which may result in codon changes, cellular development defects and potential carcinogenic susceptibility. Thus, the imbalance in ADAR expression or activity may be a causative factor in a variety of diseases including cancer (3). This article reviews the structure and function of ADAR, ADAR-mediated RNA editing, the role of ADAR in cancer and related clinical application.

\section{The ADAR family}

ADAR proteins were first found in Xenopus embryos (4). ADAR genes are discovered in multicellular animals such as Drosophila melanogaster, Caenorhabditis elegans, birds, cuttlefish, and mammals including humans (5). Mammalian cells express 3 kinds of ADARs: ADAR1, ADAR2 and ADAR3. ADAR1 and ADAR2 form homodimers, whereas ADAR3 does not form dimers. ADAR3 can bind to ADAR1 and ADAR2 substrates, thereby inhibiting their activity (3). The ADAR proteins consist of two to three $\mathrm{N}$-terminal dsRBDs and a conserved C-terminal catalytic deaminase domain (ADARcd) (6). The dsRBDs select and bind targets, and ADARcd catalyzes deamination (7). The structure of inosines is similar to that of guanosine $(\mathrm{G})$, so cellular enzymes can recognize inosine as guanosine (7). In the $\mathrm{N}$-terminal region, ADAR1 contains the Z-DNA binding domains $\mathrm{Za}$ and $\mathrm{Zb}$, whose activity can influence neogenetic RNA, resulting in pre-splicing editing, which is absent in ADAR2 and ADAR3 (3). The ADAR1 protein has two isoforms, the p110 and p150 isoforms. P110-mediated editing is in the nucleus, while p150-mediated editing is in the nucleus and cytoplasm (8). ADAR2 is mainly in the nucleus, especially the nucleolus (9).

ADAR editing sites are currently estimated at over 
100 million in the human genome (10), most of which occur in the short interspersed elements (SINEs) of introns and 3' untranslated regions (3'-UTRs) in mature mRNAs and pre-mRNAs (11). Merely $0.4 \%$ of the editing takes place in the code sequences (12). ADAR editing occurs mainly in the Alu elements, which are about 300 bp long in mRNA. The Alus element is abundant in adenosine (11). ADAR can act on mRNA, miRNA, lncRNA and siRNA (13). ADAR editing can affect many biological processes, including increasing transcriptomic diversity and protecting cellular dsRNA from silencing and improper immune activation (14).

ADARs are critical for growth and development in animal models (6). ADAR1 is expressed at the highest level among the vertebrate enzymes (11). ADAR2 is expressed in almost all body parts and most abundantly in brain tissue (3). The ADAR2 transcript peaks in the CNS, particularly in the hippocampus, thalamus, subthalamic nuclei, globus pallidus, and cerebellar peduncles (11). Mice lacking ADAR1 die during embryonic stages with hemopoietic defects, widespread apoptosis, liver failure and IFN overexpression (15-18). ADAR2 knockout phenotypes are less severe than those of ADAR1 (19). ADAR2 edits the critical Q/R site in Gria2 transcript. ADAR2 knockout mice die of seizures caused by Gria2 under-editing. A knock-in editing-equivalent A-to-G mutation in the AMPA receptor subunit gene encoded by Gria2 transcript prevents seizures and death. The editing activity of ADAR2 is essential for normal development (20). ADAR expression imbalance results in many diseases including cancer, amyotrophic lateral sclerosis, dyschromatosis symmetrica hereditaria and Aicardi-Goutières syndrome $(3,21)$.

ADAR3 is resembling to ADAR1 and ADAR2 in sequence and structure. However, ADAR3 does not display deaminase activity affecting physiological functions (22). The express of ADAR3 is only in the brain (23) and has negative correlation with the editing level of the brain, suggesting that ADAR3 is a negative regulator of ADAR2 editing (11). In glioblastoma multiforme (GBM), ADAR3 competes to Gria2 binding and editing with ADAR2 at the RNA-binding domain. ADAR3 might regulate tumorigenesis in cancer of the brain through regulating ADAR2/ADAR1-mediated editing (22).

ADARs have editing-independent effects on gene expression $(24,25)$. For example, no significant correlation $(\mathrm{r}<0.05)$ between changes in gene expression and editing levels is observed after ADAR1 knockdown. The location and number of editing sites for each transcript are independent of changes in expression after ADAR1 knockout. These evidences suggest that ADAR1 can regulate gene expression independent of deamination activity (26). In-depth exploring functions of ADARs would create new ideas that may lead to the development of cancer treatments.

\section{A-to-I RNA editing}

RNA editing is a post-transcriptional mechanism that modifies RNA nucleotides without changing the template genomic DNA (27). Dysregulation of the editing process has serious consequences, and abnormal RNA editing within the transcriptome range detected in many kinds of tumors (21). A-to-I editing is the most common form in RNA base modification (10). The functional impact of A-to-I editing includes alteration of protein amino acid sequence, alterations in pre-mRNA splicing modes, alterations in miRNA seed sequences, alterations in gene regulation, alterations in target RNA stability, effects on lncRNA function, RNA interference and the formation of ribonucleoprotein (RNP) complexes, and transcript stability and subcellular localization $(22,27,28)$. Furthermore, A-to-I editing in long double-stranded regions may prevent silencing of host RNAs and self-RNAs inappropriate activation of immune response (14).

Many A-to-I RNA editing events occur in cancers and are related to clinic $(13,29,30)$. A-to-I editing can derive neoantigens (21) which immune system can recognize. Furthermore, RNA editing has temporal diversity, so there is no accumulation of mutations in the genome of the progeny cells in the tumor. The property helps promote the generation of chemotherapy-resistant cells (26). Identifying driver RNA editing sites could provide new therapeutic and diagnostic approaches.

\section{ADAR in cancer}

Growing evidence shows that ADAR-mediate RNA editing is the important contributor to pathogenesis. Bioinformatics analysis and experimental studies have shown that ADAR-mediated editing patterns and activities in tumors are different from normal tissues (31). The following summarizes the important targets and mechanisms of ADAR in cancer (Table 1).

\section{$R N A$ editing-dependent roles of ADAR1 in cancer}

The mechanisms of ADAR1 in tumors are complex and 
Table 1 Known roles of ADAR in cancer

\begin{tabular}{|c|c|c|c|c|}
\hline Targets & ADAR & Cancer types & Finding & References \\
\hline & & NSCLC, BC, PRAD & antizyme & $(34-36)$ \\
\hline GLI1 & ADAR1 & MM & $\begin{array}{l}\text { Edited GLI1 activates the Hedgehog signaling pathway and promotes } \\
\text { malignant regeneration of } \mathrm{MM} \text { and lenalidomide resistance in vitro }\end{array}$ & $(37,38)$ \\
\hline \multirow[t]{2}{*}{ BLCAP } & ADAR1 & $\mathrm{CC}, \mathrm{HCC}$ & $\begin{array}{l}\text { Edited BLCAP increases cell proliferation by activating the Akt/mTOR } \\
\text { signaling pathway or the pro-survival protein STAT3 }\end{array}$ & $(40,41)$ \\
\hline & ADAR2 & $\begin{array}{l}\text { Astrocytoma, CRC, } \\
\text { bladder cancer }\end{array}$ & $\begin{array}{l}\text { Decreased editing levels of BLCAP correlates with increased histological } \\
\text { malignancy }\end{array}$ & $(42)$ \\
\hline Pri-let-7 & ADAR1 & CML & $\begin{array}{l}\text { Reduction of let- } 7 \text { levels enhances the self-renewal ability of leukemic } \\
\text { stem cells }\end{array}$ & $(45)$ \\
\hline PU.1 & ADAR1 & CML & Increased hematopoietic differentiation toward the myeloid lineage & $(46)$ \\
\hline miR-200b & ADAR1 & $\begin{array}{l}\text { HNSC, KIRP, THCA, } \\
\text { UCEC }\end{array}$ & Edited miR-200b promotes cell invasion and migration & $(47)$ \\
\hline PCA3 & ADAR1 & Prostate cancer & Cancer cell proliferation, adhesion and migration & $(48)$ \\
\hline miR-455-5p & ADAR1 & Melanoma & Edited miR-455-5p reduces tumor growth and metastasis & (49) \\
\hline miR-378a-3p & ADAR1 & Melanoma & $\begin{array}{l}\text { Edited miR-378a-3p suppresses the malignant phenotype and melanoma } \\
\text { metastasis }\end{array}$ & $(50)$ \\
\hline \multirow[t]{2}{*}{ GluA2 } & ADAR2 & GBM & $\begin{array}{l}\text { Edited GluA2 produces } \mathrm{Ca}^{2+} \text { impermeable AMPA channels that inhibit cell } \\
\text { migration and induces apoptosis }\end{array}$ & $(55-58)$ \\
\hline & ADAR3 & astrocytoma & $\begin{array}{l}\text { ADAR3 negatively regulates the editing of GluA2 at the } Q / R \text { site in } \\
\text { astrocytoma }\end{array}$ & (59) \\
\hline $\operatorname{miR} 221$ & ADAR2 & GBM & MiR-221, miR-222, and miR-21 have oncogenic & $(60,61)$ \\
\hline miR222 & ADAR2 & GBM & Function by inhibiting tumor suppressor protein & \\
\hline miR-21 & ADAR2 & GBM & p27kip1 (mir-221 and 222) and PDCD4 (miR-21) & \\
\hline $\operatorname{miR}-376^{*}$ & ADAR2 & GBM & $\begin{array}{l}\text { Unedited miR- } 376^{*} \text { enhances invasion and migration whereas edited } \\
\text { miR-376a* inhibits GBM progression }\end{array}$ & $(62)$ \\
\hline miR-589-3p & ADAR2 & GBM & Unedited miR589-3p inhibits the tumor suppressor protein PCDH9 & (63) \\
\hline COPA & ADAR2 & $\mathrm{HCC}$ & $\begin{array}{l}\text { The editing level of COPA is inversely correlated with the pathogenesis of } \\
\text { HCC }\end{array}$ & $(64)$ \\
\hline
\end{tabular}

Table 1 (continued) 
Table 1 (continued)

\begin{tabular}{|c|c|c|c|c|}
\hline Targets & ADAR & Cancer types & Finding & References \\
\hline miR-122 & ADAR2 & $\mathrm{HCC}$ & MiR-122 regulates the host gene and viral life cycle of HBV and HCV & $(66,69)$ \\
\hline SLC22A3 & ADAR2 & Esophageal cancer & $\begin{array}{l}\text { Edited SLC22A3 is increased in familial esophageal cancer and is } \\
\text { associated with lymph node metastasis }\end{array}$ & $(71)$ \\
\hline miR-142 & $\begin{array}{l}\text { ADAR1 and } \\
\text { ADAR2 }\end{array}$ & AML & $\begin{array}{l}\text { The miR-142s gene is located at a translocation site associated with } \\
\text { aggressive B cell leukemia }\end{array}$ & $(72)$ \\
\hline miR-222 & ADAR1 & Melanoma & $\begin{array}{l}\text { ADAR1 levels are decreased in melanoma. ADAR1 knockdown enhances } \\
\text { miR-222 biogenesis and inhibits the expression of ICAM1 }\end{array}$ & $(76)$ \\
\hline COG3 I/V & ADAR3 & GBM & $\begin{array}{l}\text { Excessive editing at the COG3 I/N site plays a pro-tumoral role in GBM and } \\
\text { is associated with poor prognosis }\end{array}$ & $(77)$ \\
\hline PTPN6 & $\begin{array}{l}\text { ADAR1 or } \\
\text { ADAR2 }\end{array}$ & AML & $\begin{array}{l}\text { PTPN6 plays an anti-cancer role by downregulating the broad spectrum } \\
\text { growth-promoting receptors and cytokine receptors }\end{array}$ & $(78)$ \\
\hline $\mathrm{RHOQ}$ & $\begin{array}{l}\text { ADAR1 or } \\
\text { ADAR2 }\end{array}$ & $\begin{array}{l}\mathrm{CRC}, \mathrm{GC}, \mathrm{HCC} \text {, } \\
\text { lung cancer }\end{array}$ & $\begin{array}{l}\text { Edited RHOQ mediates dynamic actin cytoskeletal recombination, thus } \\
\text { increasing the invasive potential }\end{array}$ & $(29)$ \\
\hline
\end{tabular}

HCC, hepatocellular carcinoma; ESCC, esophageal squamous cell carcinoma; NSCLC, non-small-cell lung cancer; CRC, colorectal cancer; BC, breast cancer; PRAD, prostate adenocarcinoma; MM, multiple myeloma; MB, medulloblastoma; BCC, basal cell carcinoma; CC, cervical cancer; LUAD, lung adenocarcinoma; CML, chronic myeloid leukemia; HNSC, head and neck squamous cell carcinoma; KIRP, kidney renal papillary cell carcinoma; THCA, thyroid carcinoma; UCEC, uterine corpus endometrial carcinoma; OC, ovarian cancer; GBM, glioblastoma multiforme; AML, acute myeloid leukemia; GC, gastric cancer.

it can promote or suppress cancer in different tumors (Figure 1). ADAR1-mediated editing of AZIN1 increases and promotes carcinogenesis in hepatocellular carcinoma (HCC). RNA-Seq shows that two ADAR1 transcript variants encoding the $\mathrm{p} 110$ and $\mathrm{p} 150$ isoforms are relatively abundant in liver tissue, among which p110 is the predominant form (32). Transcriptome sequencing of tumor tissue shows that ADAR1-mediated editing permutes serine to glycine at AZIN1 residue 367, inducing AZIN1 to transfer from the cytoplasm to the nucleus and tumorigenic phenotype, thereby enhancing the invasive capability $(32,79)$. AZIN1 is homologous to ornithine decarboxylase (ODC), and its affinity for binding to enzymes is higher than that of ODC. Antizyme is a synthetic mammalian protein with ribosomal frameshift function. Antizyme binds to and promotes the degradation of ODC and cyclin D1 (CCND1) to adjust cell growth. Antizyme degrades ODC and inhibits polyamine uptake, thereby inhibiting cell proliferation, which suggests that it acts as a tumor suppressor gene (79). The affinity of edited AZIN1 protein for antizyme is stronger than wild-type form, and can neutralize the degradation of ODC and CCND1 mediated by antizyme, thereby increasing protein stability. ODC and CCND1 are important for regulating G1/S conversion, and their raised levels can increase protein synthesis, which is necessary to enter cell cycle (32). Accumulation of ODC and CCND1 leads to increase in cell proliferation, tumor initiation and metastasis (33). In summary, AZIN1 exerts carcinogenic effect by restraining antizyme activity. In addition, ADAR1 expression and AZIN1 over-editing are 


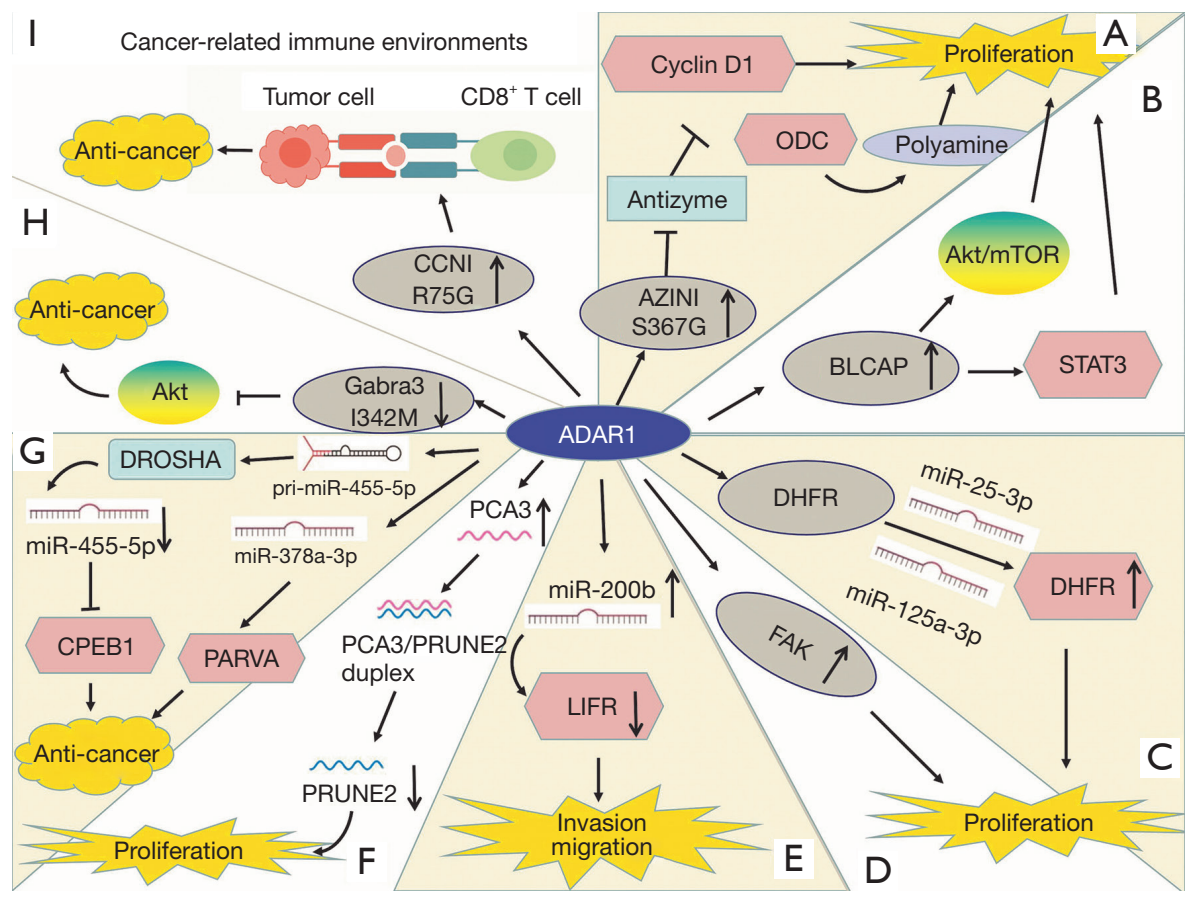

Figure 1 The roles of ADAR1-mediated A-to-I RNA editing in cancer. (A,B,C,D,E,F) ADAR1 upregulation leads to increased editing of target mRNAs, such as AZINI, BLCAP, DHFR, FAK, leukemia inhibitory factor receptor (LIFR), and prostate cancer antigen 3 (PCA3) as well as miRNAs such as miR-200b, which contribute to cancer progression through various signaling pathways. (G,H) ADAR1 expression is downregulated in melanoma and BC, which decreases editing of miR-455-5p, miR-378a-3p, and Gabra3. Edited miR-455-5p, miR-378a-3p, and GABRA3 suppress cancer cell invasion and metastasis. (I) ADAR1 plays a role in cancer-related immune environments.

closely related to the occurrence, development, metastasis and recurrence of HCC (32). HCC occurrence involves other editing targets such as FLNB and COPA (64). In addition to HCC, AZIN1 levels are substantially elevated in non-small-cell lung cancer (NSCLC) (35), esophageal squamous cell carcinoma (ESCC) (34), colorectal cancer (CRC) (33), BC (13) and prostate adenocarcinoma (36). High-level AZIN1 editing is the prognostic indicator of population and tumor-free survival, and is the independent risk factor for lymph node and distant metastasis (33) (Figure 1A).

In RNA editing enzyme related to Multiple myeloma $(M M)$, the expression of ADAR1 is the most abundant $(37,80)$. Both 1q21 amplification and environmental factors such as inflammatory cytokines and immunomodulatory drugs (IMiDs) regulate A-to-I editing activity (38). Amplified ADAR1 edits glioma-associated oncogene 1 (GLI1), leading to an $\mathrm{R} / \mathrm{G}$ amino acid change at residue 701 (38). This stabilizes GLI1 expression through blocking binding to negative regulator, suppressor of fused (SUFU) (37). Edited GLI1 has elevated transcriptional activity, and activates the Hedgehog signaling pathway, thereby promoting malignant regeneration of $M M$ and lenalidomide resistance in vitro $(81,82)$. Interestingly, in basal cell carcinoma and medulloblastoma, edited GLI1 exerts antitumorigenic effect. ADAR1-edited GLI1 (R701G) shows reduced oncogenic potential because edited GLI1 becomes less accostable to activator, dual specificity tyrosinephosphorylation-regulated kinase 1A (DYRK1A) (37). Further research is needed to clarify the influencing factors of the tumorigenic and anti-tumor effects of ADAR1mediate editing (Figure 2).

Transcriptome analysis shows that endonuclease 8-like 1 (NEIL1) is also highly edited by ADAR1 in MM and is clinically important. NEIL1 is a basal excision repair protein involved in DNA damage repair. The edited NEIL1 shows reduced oxidative damage repair ability, enhancing cell sensitivity to combination treatment with agents inducing single-stranded and double-stranded DNA breaks (39) (Figure 2).

Bladder cancer-associated protein (BLCAP) was first identified in invasive bladder cancer (83). BLCAP inhibits 


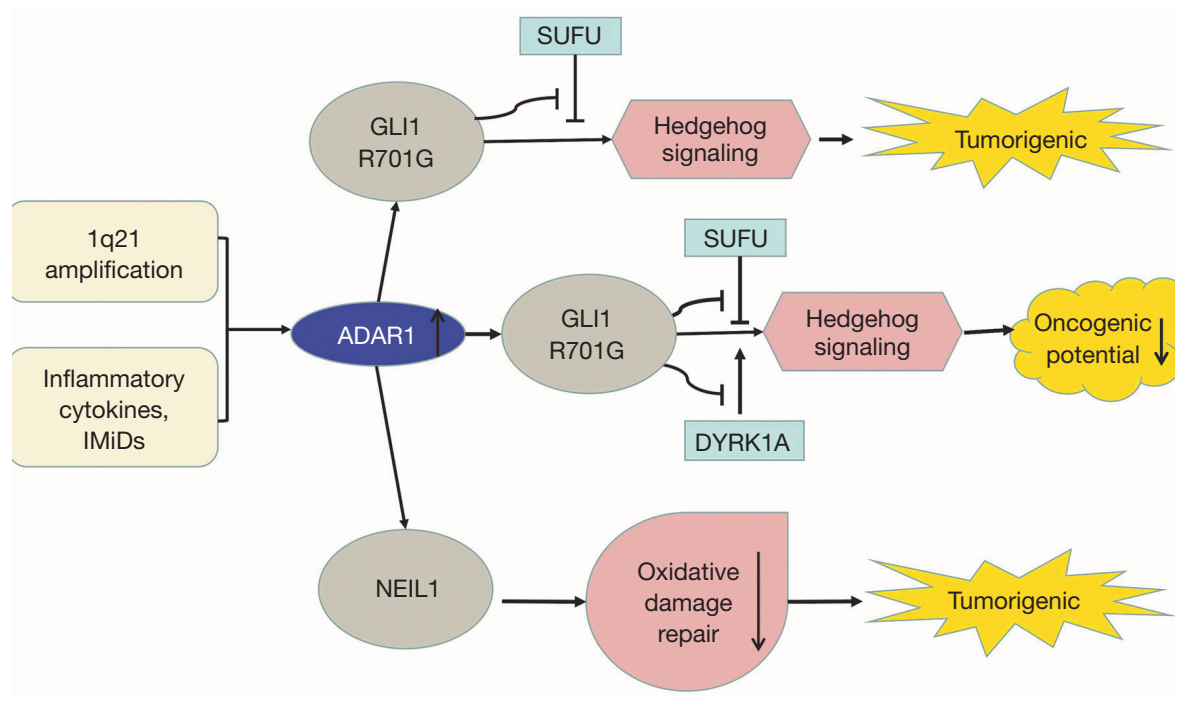

Figure 2 The roles of ADAR1-mediated RNA editing in Multiple myeloma (MM), basal cell carcinoma (BCC) and medulloblastoma (MB). In MM, 1q21 amplification, inflammatory cytokines and immunomodulatory drugs (IMiDs) upregulate ADAR1 editing activity. Increased ADAR1 edits glioma-associated oncogene 1 (GLI1) and stabilizes GLI1 expression by preventing the binding of its negative regulator, suppressor of fused (SUFU). Edited GLI1 activates the Hedgehog signaling pathway and promote malignant regeneration of MM. In MB and BCC, edited GLI1 is less accessible to its activator, Dual specificity tyrosine-phosphorylation-regulated kinase 1A (DYRK1A) and shows reduced oncogenic potential. In addition, edited endonuclease 8-like 1 (NEIL1) in MM shows reduced oxidative damage repair ability.

tumorigenesis by stimulating cell apoptosis and inhibiting proliferation $(84,85)$. ADAR1 edits many sites in BLCAP YXXQ domain to promote cervical cancer (CC) (40). Overexpression of BLCAP leads to growth inhibition, S-phase arrest, and apoptosis (84). The BLCAP transcript coding region is hyper-edited in CC (40) and in HCC (41). BLCAP editing activates Akt/mTOR signal pathway and the pro-survival protein STAT3 to promote cellular proliferation (40). By contrast, the editing levels of BLCAP are decreased in astrocytoma, bladder cancer, and CRC, and correlated with increased histological malignancy of the tumors, which is mediated by ADAR2 (42). ADAR1 and ADAR2 have different effects on BLCAP editing and further research is needed to clarify the reasons for this difference (Figure 1B).

ADAR1 expression is increased in BC $(13,86,87)$. ADAR1 edits the pro-survival gene dihydrofolate reductase (DHFR) in 2 inverted Alu within the $3^{\prime}$-UTR of its transcript. DHFR is involved in folate metabolism. RNA editing prevents miRNA-mediated silencing of DHFR, thereby stabilizing its mRNA. DHFR is the target for methotrexate as well. ADAR1 binds to and edits miR-25-3p and miR-125a-3p to upregulate the expression of DHFR, thereby promoting cell proliferation and methotrexate resistance (43)
(Figure 1C).

ADAR1-mediated editing occurs in focal adhesion kinase (FAK) at intron 26, which is a tumor metastasis promoting factor. In lung adenocarcinoma (LUAD), edited FAK stabilizes the FAK mRNA and protein, promoting invasion and recurrence (44) (Figure 1D).

As previously stated, ADAR1 is involved in embryonic hematopoiesis $(15,18)$. In blast crisis chronic myeloid leukemia (BC CML), BCR-ABL1 amplification upregulates expression of IFN-g pathway genes, and then inflammatory stimulation drives the expression of ADAR1 p150. In addition, JAK2 activation also promotes ADAR1 expression (46). The expression of ADAR1p110 remains unchanged (30). ADAR1 is required for leukemia cell survival (88). Overexpression of ADAR1 induces the pluripotency gene LIN28 and promotes pri-let-7 editing, causing a decrease in let-7 family (89). The decrease in let-7 increases the selfrenewal ability of the leukemic stem cell (LSC) (45). In addition, increased levels of ADAR1 p150 are related to the upregulation of the myeloid transcription factor PU.1 and the downregulation of the erythroid transcription factor GATA1, which lead to myeloid lineage skewing. However, the effect of ADAR1 on PU.1 expression is not clear (46). ADAR1 p150 overexpression in cultured blood progenitor 


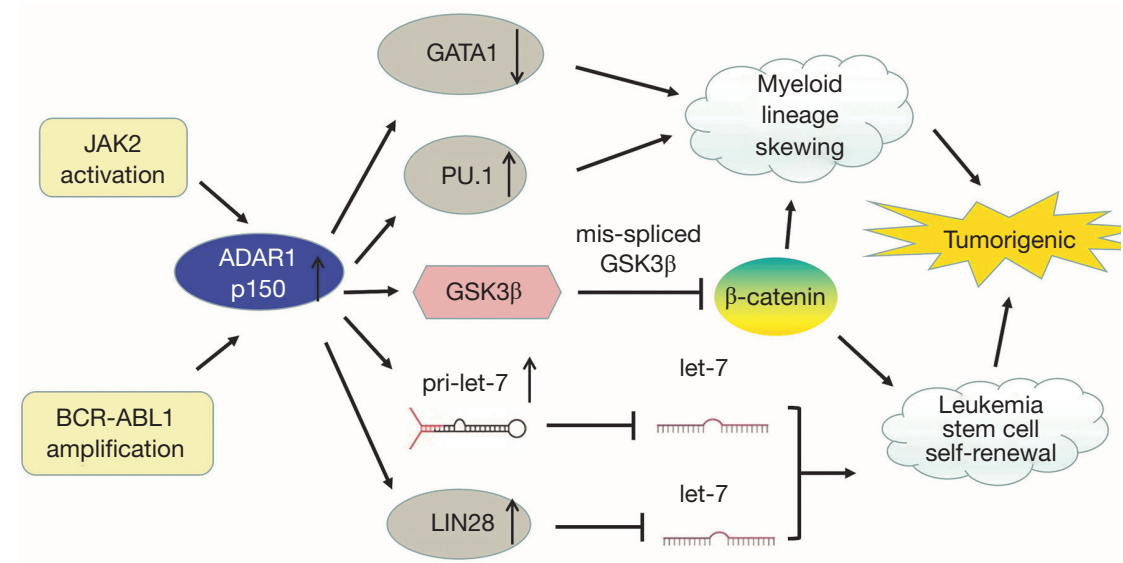

Figure 3 The roles of ADAR1-mediated RNA editing in chronic myeloid leukemia. JAK2 activation and BCR-ABL1 amplification increase ADAR1 p150 expression. Increased ADAR1 p150 upregulates the myeloid transcription factor PU.1 and downregulates the erythroid transcription factor GATA1, which lead to myeloid lineage skewing. ADAR1 p150 overexpression induces reprogramming of myeloid progenitor cells, potentially through the generation of a mis-spliced version of GSK3 $\beta$ mRNA. The mis-spliced GSK3 $\beta$ cannot downregulate $\beta$-catenin, which is essential for cell self-renewal. ADAR1 overexpression induces the pluripotency gene LIN28 and promotes pri-let-7 editing, reducing let-7 production and further promoting the self-renewal ability of leukemic stem cells.

cells induces reprogramming of myeloid progenitor cells. This increases hematopoietic differentiation to myeloid lineage, possibly via the upregulation of PU.1 and generation of a mis-spliced version of glycogen synthase kinase $3 \beta$ (GSK3 $\beta)$ mRNA. The identification of misspliced GSK3 $\beta$ as a negative regulator of $\beta$-catenin suggests that alternative splicing induced by $\mathrm{ADAR} 1$ promotes $\mathrm{CML}$ progression. $\beta$-catenin plays an important role in cell selfrenewal, but mis-spliced GSK3 $\beta$ cannot downregulate $\beta$-catenin. ADAR1 was therefore identified, for the first time, as the driving factor for reprogramming malignant progenitor cells to self-renewing LSC (46) (Figure 3).

Over-editing of miR-200b can be found in a variety of cancers and is correlated with poor patient survival. Edited miR-200b by ADAR1 promotes cell invasion and migration mainly via its reduced ability to inhibit the epithelialmesenchymal transition (EMT) regulators ZEB1 and ZEB2 and the concomitantly acquired ability to repress new targets, such as the metastasis suppressor leukemia inhibitory factor receptor (LIFR) (47) (Figure 1E).

The lncRNA prostate cancer antigen 3 (PCA3) is upregulated in prostate cancer (90). PCA3 is dominantnegative oncogene. ADAR1-mediated editing of PCA3 increases its stability and expression. PCA3 is antisense to tumor suppressor gene prune homolog 2 (PRUNE2), and forms a duplex with the PRUNE2 pre-mRNA. ADAR1-mediated A-to-I editing of the PCA3/PRUNE2 duplex at multiple sites downregulates PRUNE2 and upregulates PCA3 expression, thereby increasing cancer cell proliferation, adhesion, and migration (48) (Figure 1F).

The expression of ADAR 1 is significantly lower in metastatic melanoma than in melanocytes (91). Activation of cyclic AMP-responsive element binding protein (CREB) downregulates ADAR1 expression (49,50). Knockdown of ADAR1 promotes the growth and metastasis of melanoma by controlling the biogenesis of oncogenic or tumor inhibiting miRNAs. Shoshan et al. found that editing primiR-45 5-5p by ADAR 1 prevents cleavage by drosha ribonuclease III (DROSHA), resulting in a low level of mature miR-455-5p. Wild-type miR-455-5p inhibits tumor suppressor cytoplasmic polyadenylation element-binding protein 1 (CPEB1) to stimulate tumor proliferation and metastasis, whereas edited miR-455-5p has the opposite effect (49). In addition, ADAR1 mediated miR-378a-3p editing at +18 site is only in non-metastatic melanoma cells, whereas the wild-type form accumulates in metastatic cells. The oncogene PARVA promotes progress and metastasis of melanoma. Edited miR-378a-3p downregulates the expression of PARVA to prevent melanoma development and metastasis (50) (Figure 1G).

The expression of ADAR 1 is lower in metastatic $\mathrm{BC}$ cells than in noninvasive cells (51). ADAR1 edits the conversion of isoleucine to methionine ( $/ / \mathrm{M})$ in the GABAA receptor $\alpha-3$ (Gabra3) transcript in the brain (92). The edited form 


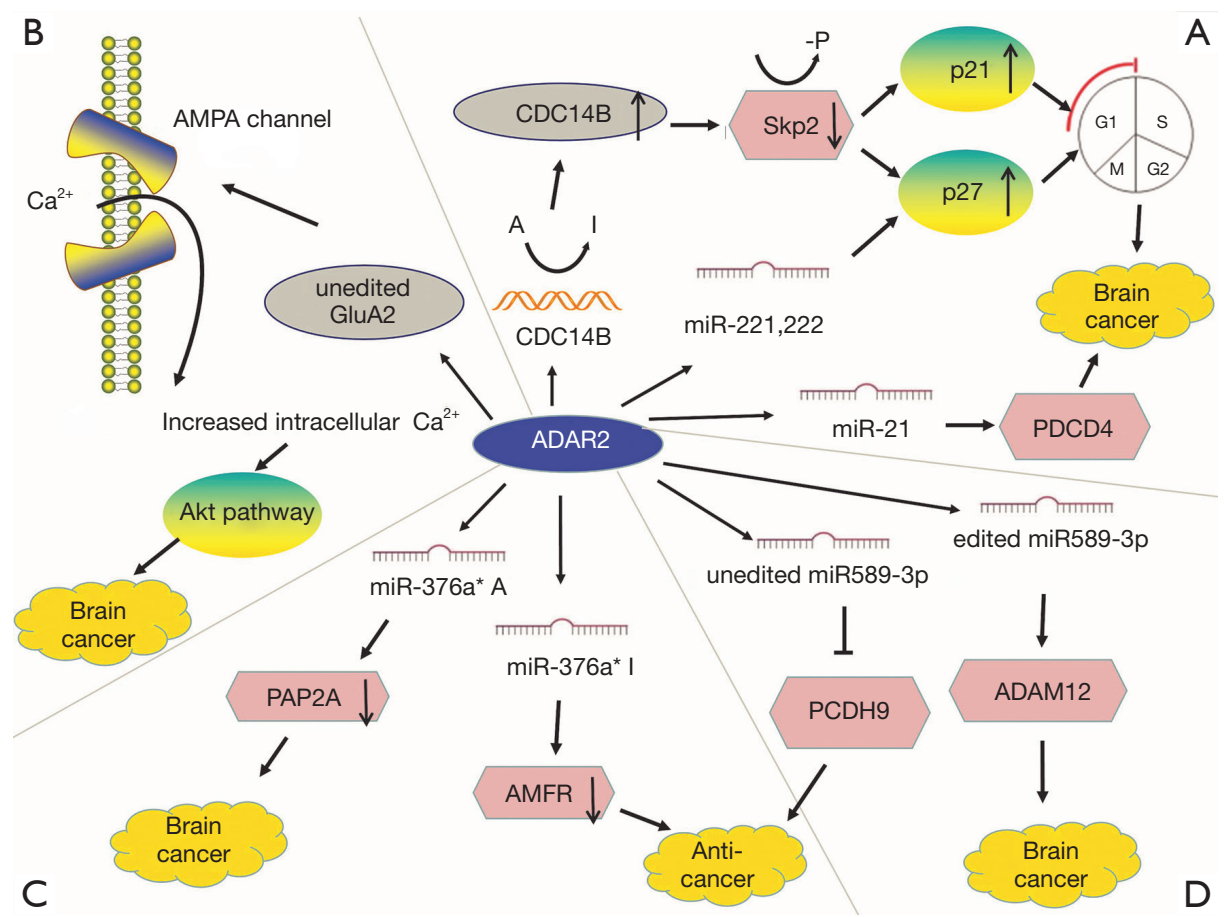

Figure 4 The roles of ADAR2-mediated RNA editing in brain cancer development. ADAR2 expression or editing activity is often low in cancer. Editing levels of ADAR2 targets such as CDC14B, GluA2, miR-221, miR-222, miR-21, miR-376a* and miR-589-3p are decreased, contributing to brain cancer development, especially in glioblastoma multiforme.

of Gabra3 is expressed only in non-invasive BC tissues, and not in metastatic tumors $(51,93)$. In BC, GABRA3 activates the AKT pathway, which promotes cell migration, invasion, and metastasis (51). The expression of edited GABRA3 decreases on the cell surface (94), thereby inhibiting AKT activation and BC metastasis (51) (Figure $1 H$ ).

ADAR1 also plays a role in cancer-related immune environments. In ovarian cancer, melanoma, and BC, human leukocyte antigen (HLA) molecules express increased ADAR1-edited peptides, including cyclin I (CCNI), which induce antigen-specific killing of oncocytes by CD8+ T cells. This suggests the possibility of exploring immunotherapeutic approaches based on RNA editing (52) (Figure 11).

\section{$R N A$ editing-dependent roles of ADAR2 in cancer}

ADAR2 mediated editing can inhibit tumor occurrence and metastasis. ADAR2 is important in brain development and function (95). ADAR2 activity decreases in high-grade astrocytoma and GBM $(31,60)$. Cells which overexpress ADAR2 are mainly concentrated in G1 phase (54). The CDC14B transcript is a novel candidate gene because it regulates S-phase entry through a process dependent on the E3 ligase S-phase kinase-associated protein 2 (skp2) (53). ADAR2 promotes the upregulation of CDC14B by editing multiple sites in the CDC14B phosphatase pre- mRNA intron 7 , leading to degradation of SKP2 $(53,54)$. ADAR2 silencing inhibits edits of entire recognized sites in CDC14B transcript and decreases the expression level of CDC14B mRNA. Decreased CDC14B expression is related to increased astrocytoma invasiveness and poor prognosis (54). The CDC14B phosphatase acts upstream of the Skp2/p21/ p27 pathway and modulates GBM proliferation $(53,54)$. In glioblastoma, Skp2 overexpression downregulates p21 and p27, which regulate G1/S cell cycle transition $(96,97)$. The Skp2 protein is an E3-ligase and drives the ubiquitination and degradation of p27Kip1 and p21Cip1/Waf1/Sdi1 (98). CDC14B reduces Skp2 by Ser64 dephosphorylation, inhibiting the degradation of p21 and p27 (53). P21 and p27 are tumor suppressor genes. Active ADAR2 downregulates Skp2 and upregulates p21/p27 (54). In addition, the strong upregulation of active CDC14B further decreases the proliferation of $\mathrm{U} 118$ cells, possibly because the protein acts simultaneously at cell cycle checkpoints G1/S46 and G2/M, indicating that high ADAR2 expression significantly reduces 
cell multiplication $(54,55)$. Overall, genes are rarely mutated in GBM, indicating that post-transcriptional regulation is critical in the pathology of GBM (97) (Figure 4A).

In glioblastoma cells, GluA2 induces apoptosis (56), whereas in astrocytoma cells, ADAR2 overexpression completely edits the GluA2 Q/R site but does not have the same effect (55). Glutamate ionotropic receptor AMPA type subunit 2 (GluA2 or GRIA2) is a subunit of the AMPA glutamate receptor family, in which four subunits are combined in different ways to form a mature receptor. Activation of the mature receptor by the ligand glutamate converts it into neuronal excitatory ion channel. ADAR2 edits GluA2 at Q/R site, which makes the channel nearly impermeable to $\mathrm{Ca}^{2+}$ ions, thereby reducing intracellular calcium concentration (99). In glioblastoma, $\mathrm{Q} / \mathrm{R}$ site editing reduces to $69-88 \%$ because of the significantly reduced editing activity of ADAR2 (57). High expression of the $\mathrm{Ca}^{2+}$ permeable AMPA receptor subunit in GBM indicates that the change of $\mathrm{Ca}^{2+}$ influx is associated with carcinogenesis. Edited GluA2 produces $\mathrm{Ca}^{2+}$ impermeable AMPA channels that inhibit cell migration and induce apoptosis, whereas unedited GluA2 promotes the malignant characteristics of cells (56). Unedited GluA2 and intracellular $\mathrm{Ca}^{2+}$ wave propagation induce the phosphorylation and activate Akt pathway in GBM (58) (Figure 4B).

In glioblastoma cells, ADAR2 regulates the expression of many miRNAs (100). ADAR2 editing prevents corresponding precursors from maturing to miR-221, miR-222 and miR21 to restrict their expression (60). Decreased ADAR2 activity reduces the inhibition of the three oncomiRs, thereby promoting tumor growth and migration (101). ADAR2-mediated p27 downregulation is also related to miRNAs edited by ADAR2 in the brain (60). The three oncogenes inhibit the tumor suppressor protein p27kip1 and programmed cell death protein 4 (PDCD4) (61). In GBM, failure to edit miR-21 and miR-221/222 results in the downregulation of their respective targets PDCD4 and p27Kip1 (60) (Figure 4A).

MiR-376* is another miRNA that is under-edited in glioblastoma. Although the expression of miR-376* clusters does not change, ADAR2-mediated pri-miRNA editing is decreased in GBM, resulting in reduced seed sequence editing in mature miRNAs. The overexpression of unedited miR-376* promotes invasion and migration, whereas edited miR-376a* inhibits GBM progression. ADAR2 can induce a switch between the oncogenic and tumor-suppressive activities of miRNAs by changing target specificity.
ADAR2-edited miR376a* binds to the 3'-UTR of autocrine motility factor receptor (AMFR), a receptor for the tumor motility-stimulating protein AMF, and downregulates it, thereby inhibiting tumor migration and invasion. Unedited miR376a* binds to the 3'-UTR of Ras-related protein 2a (RAP2A) mRNA to downregulate its expression, thereby promoting glioblastoma cell invasion. RAP2A acts on actin remodeling and exerts tumor suppressive effects. Invasion experiments show that AMFR upregulation has a greater effect on increasing the aggressiveness and migration of glioma than RAP2A downregulation. This study illustrated how RNA editing changes target specificity, leading to different effects between edited and unedited miRNAs (62) (Figure 4C).

In advanced GBM, miR-589-3p editing levels are significantly decreased. Unedited miR-589-3p inhibits protein protocadherin 9 ( $\mathrm{PCDH} 9$ ) which suppress cancer development. In normal brain tissues, ADAR2 edits almost all miR-589-3p to diminish the expression of metalloproteinase domain-containing protein 12 (ADAM12), which can accelerate cancer metastasis (63) (Figure 4D).

ADAR2-mediated editing activity is generally low in GBM, particularly editing of GluA2 mRNA, although the expression of ADAR2 is not correspondingly downregulated (57). Both ADAR1 and ADAR3 are upregulated in brain tumors (59), however, decreased expression of all ADAR genes was reported in a different study (31). The low editing rate in glioblastoma may be due to inhibition of ADAR2 editing by overexpressed ADAR1, as suggested by in vitro experiments showing the dosedependent inhibitory effect of ADAR1 overexpression on ADAR2 in vitro (55). Overexpression of ADAR3 may also be involved, as suggested by its effect on inhibiting GluA2 editing (59). It is also possible that the splicing variant of ADAR2 with reduced catalytic activity is the expressed form (57).

In addition to GBM, ADAR2 suppresses tumorigenicity in other cancers. ADAR2 downregulation occurs in approximately $50 \%$ probability in HCC, whereas increased ADAR2 expression in ADAR-deficient HCC weakens carcinogenic potential (64). The suppressive function of ADAR2 in HCC is mediated by edited coatomer protein complex subunit $\alpha$ (COPA) mRNA (I164V). Edited COPA is absent in invasive CRC with the EMT phenotype, resulting in liver metastasis (65). In addition, ADAR2 plays a role in regulating miR-214 and miR-122, which are reduced in HCC (66). MiR-214 promotes the occurrence 


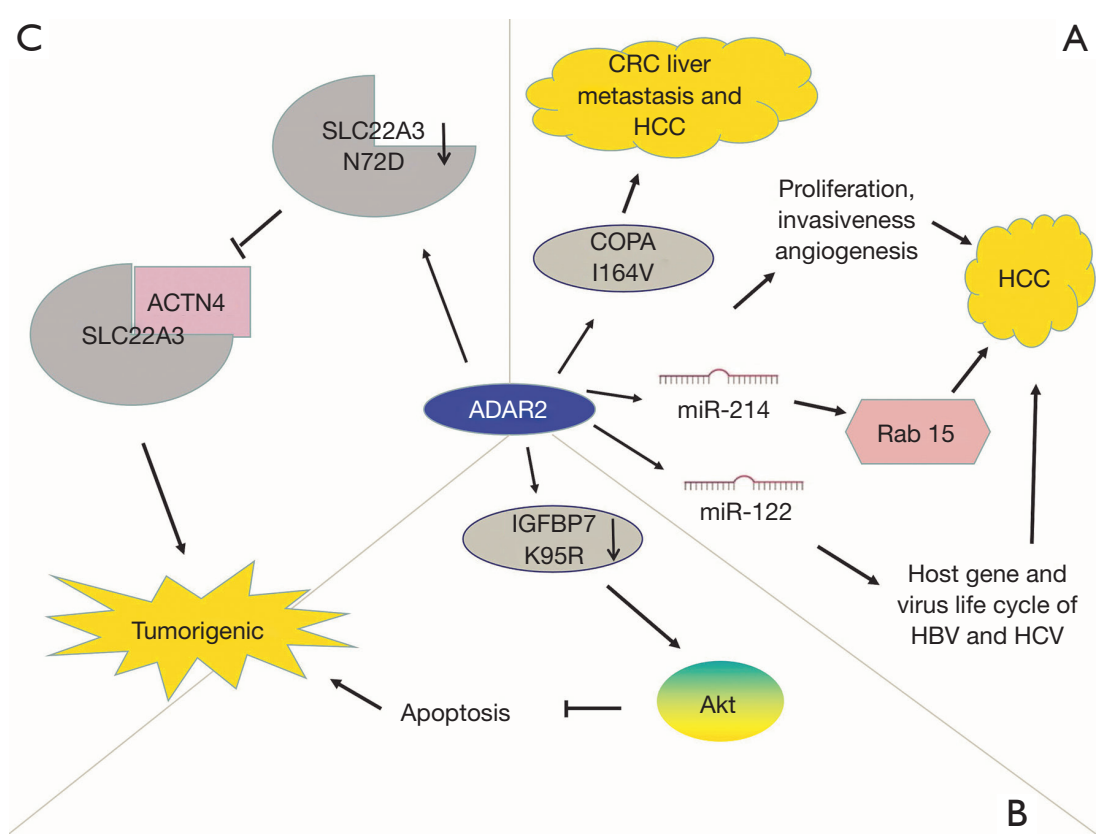

Figure 5 The roles of ADAR2-mediated RNA editing in cancer development. ADAR2 downregulation has oncogenic effects. (A) The editing level of COPA is inversely correlated with the pathogenesis of hepatocellular carcinoma (HCC). Edited COPA is absent in CRC, leading to liver metastasis. ADAR2 regulates biogenesis of miR-214 and miR-122 in HCC. The RNA precursors of miR-214 and miR-122 are targets for ADAR2 editing. ADAR2 editing decreases miR-214 and its target gene Rab15. MiR-214 regulates HCC proliferation, invasiveness, and angiogenesis. MiR-122 regulates host gene and virus life cycle of HBV and HCV. (B) In esophageal squamous cell carcinoma (ESCC), decreased expression of ADAR2 reduces the editing frequency of IGFBP7, activates the Akt pathway and inhibits apoptosis, leading to malignant phenotype. (C) In familial esophageal cancer, SLC22A3 deregulation promotes metastasis and filopodia formation through decreasing direct binding to a-actinin-4 (ACTN4).

of HCC by regulating proliferation, invasiveness, and angiogenesis $(67,68)$. An editing event leads to a decrease in RNA transcription complementary to pri-miR-214, resulting in the decline in pri-miR-214 and miR-214 and an increase in target Rab15 protein (66). Rab15 is a Ras oncogene related to retinoic-acid-induced differentiation and receptor recycling, however, its specific role in HCC remains unclear $(102,103)$. In HCC, miR-122 regulates the host gene and lifecycle of HBV and HCV (69). In summary, edited complementary antisense transcripts regulates the biogenesis of specific miRNAs involved in the pathogenesis of HCC, thus providing novel targets for the treatment of HCC (Figure 5A).

ADAR2 is downregulated in esophageal squamous cell carcinoma (ESCC) (70). Editing of insulin-like growth factor-binding protein 7 (IGFBP7) converts lysine residue into arginine (104,105). ADAR2-mediated editing stabilizes IGFBP7 by altering the protease recognition site of matriptase and inhibiting proteolytic cleavage, thereby inducing apoptosis. In ESCC, IGFBP7 is one of the pro-apoptotic genes showing decreased editing levels. Downregulation of ADAR2 in ESCC and decreased editing and expression of IGFBP7 (K95R) activate the Akt pathway, thereby inhibiting programmed cell death and promoting tumor growth (70) (Figure 5B).

ADAR2 also edits solute carrier family 22 member 3 (SLC22A3). Increased ADAR2 levels lead to editing and downregulation of SLC22A3 (N72D), which can inhibit the metastasis of esophageal cancer. SLC22A3 deregulation promotes metastasis and filopodia formation through decreasing direct binding to a-actinin-4 (ACTN4), an actinbinding protein (71) (Figure 5C).

\section{RNA editing roles of ADAR1 and ADAR2 in cancer}

The gene encoding miR-142s is located at the translocation site related to invasive $B$ cell leukemia and is highly expressed in hematopoietic tissues, whereas rarely or not 
expressed in non-hematopoietic tissues (106). MiR-142-3p expression in patients with acute myeloid leukemia (AML) is significantly lower than that in controls (72). ADAR1 p110 and ADAR2 edit two specific pri-miR-142 sites (+4 and +5 sites), which suppresses pri-miR cleavage and significantly downregulates miR-142 expression (89).

ADAR1 edits the intron of heterogeneous nuclear ribonucleoprotein L-like (HNRPLL) to generate exon E12A, which reinforces the oncogenic splicing factor serine/arginine rich splicing factor 1 , thereby promoting HNRPLL transcription. Edited HNRPLL can regulate the expression of cyclin D1 and transforming growth factor beta receptor 1 (TGFBR1) to stimulate cellular multiplication of renal and bladder carcinoma. ADAR2 can also edit HNRPLL, suggesting the existence of cross-talk between ADAR1 and ADAR2 (73).

In GC, ADAR2 edited podocalyxin-like (PODXL) codon H241R (histidine to arginine) results in reduced growth and invasiveness, which neutralizes the tumorigenic ability of unedited PODXL (74). PODXL is an oncogene that induces oncocytes migration and invasion via acting on actin-binding protein EZR (75). Unedited PODXL promotes the development of GC through adjusting cell adhesion mechanisms. In addition, ADAR 1 and ADAR2 induce synonymous (ACA>ACG; T238T) and nonsynonymous (CAC>CGC; H241R) editing of PODXL, respectively. A high rate of ADAR2/ADAR1-mediated PODXL editing (H241R) can prevent carcinogenesis. In GC, the increase in ADAR1 and decrease in ADAR2 lead to an imbalance of PODXL editing and thus an increase in unedited PODXL, resulting in tumorigenesis. Inhibition of ADAR1 or recovery of potential ADAR2 activity is a potential strategy for the treatment of GC (75).

\section{RNA editing-independent roles of ADAR}

RNA editing enzymes can function independently of RNA editing capabilities, which is related to tumor proliferation, metastasis and immune escape (6). ADAR1 and ADAR2 can directly interact with miRNAs or affect miRNA biogenesis by regulating Dicer, Drosha, DiGeorge Syndrome Critical Region 8 (DGCR8), or other important factors to modulate the expression of miRNAs $(25,100,107)$. The catalytically inactive forms of ADARs have RNA editing-independent functions.

ADAR1 levels are decreased in melanoma patients and cell lines, whereas ADAR2 levels remain unchanged. While ADAR1 level is changing, miRNA expression also changes, most of which do not experience RNA editing. ADAR1 silencing in vitro promotes malignant phenotype and metastasis, whereas ADAR1 overexpression inhibits melanoma cell proliferation independent of ADAR1 editing activity (91). MiR-17 and miR-432 overexpression induce downregulation of ADAR1 in melanoma $(49,91)$. GaloreHaskel et al. found that ADAR1 knockdown promotes miR222 biogenesis and inhibits the expression of the miR-222 target intercellular adhesion molecule 1 (ICAM1) (76). ICAM1 is the natural ligand of lymphocyte function associated antigen-1 (LFA-1), which acts as adhesion receptor of the immune system. Binding of LFA-1 and ICAM1 promotes the formation of the immune synapse (108) and activates T cells (109). In contrast, overexpression of ADAR1 upregulates ICAM1, increasing the sensitivity of tumors to TIL mediated killing. MiR-222 may be a potential marker for predicting the response of melanoma patients to ipilimumab, an immune checkpoint inhibitor (76).

\section{The role of ADAR3 in cancer}

ADAR3 is overexpressed in glioblastoma. ADAR3 negatively regulates GluA2 editing in astrocytoma. In addition, ADAR3 can directly bind to the GluA2 pre-mRNA to suppress ADAR2-mediated GluA2 editing (59). In GBM, over-editing of COG3 $\mathrm{I} / \mathrm{V}$ promotes tumorigenesis and is related to poor prognosis. This suggests that COG3 $\mathrm{I} / \mathrm{V}$ is a potential target of individualized therapy (77).

\section{The exceptions}

Some cancer-related editing targets are short of clear recognition to related editing enzymes, such as protein tyrosine phosphatase non-receptor type 6 (PTPN6) in AML and RAS homolog family member Q (RHOQ) in CRC.

AML is the first malignancy in which mRNA editing was shown to be associated with disease pathogenesis (78). PTPN6 is important for the development, proliferation and receptor-mediated mitogenic signaling of hematopoietic cells (110), and is identified as a tumor suppressor gene (111). PTPN6 exerts anti-cancer effect via reducing broad spectrum growth-promoting receptors and cytokine receptors. Edited PTPN6 produces a non-functional protein and suppresses its inhibitory action. Nevertheless, which editing enzyme editing PTPN6 remains to be further studied (78).

In CRC, edited RHOQ leads to the conversion of asparagine to serine, which increases protein activity and 
Table 2 Clinical applications of ADAR in cancer treatment

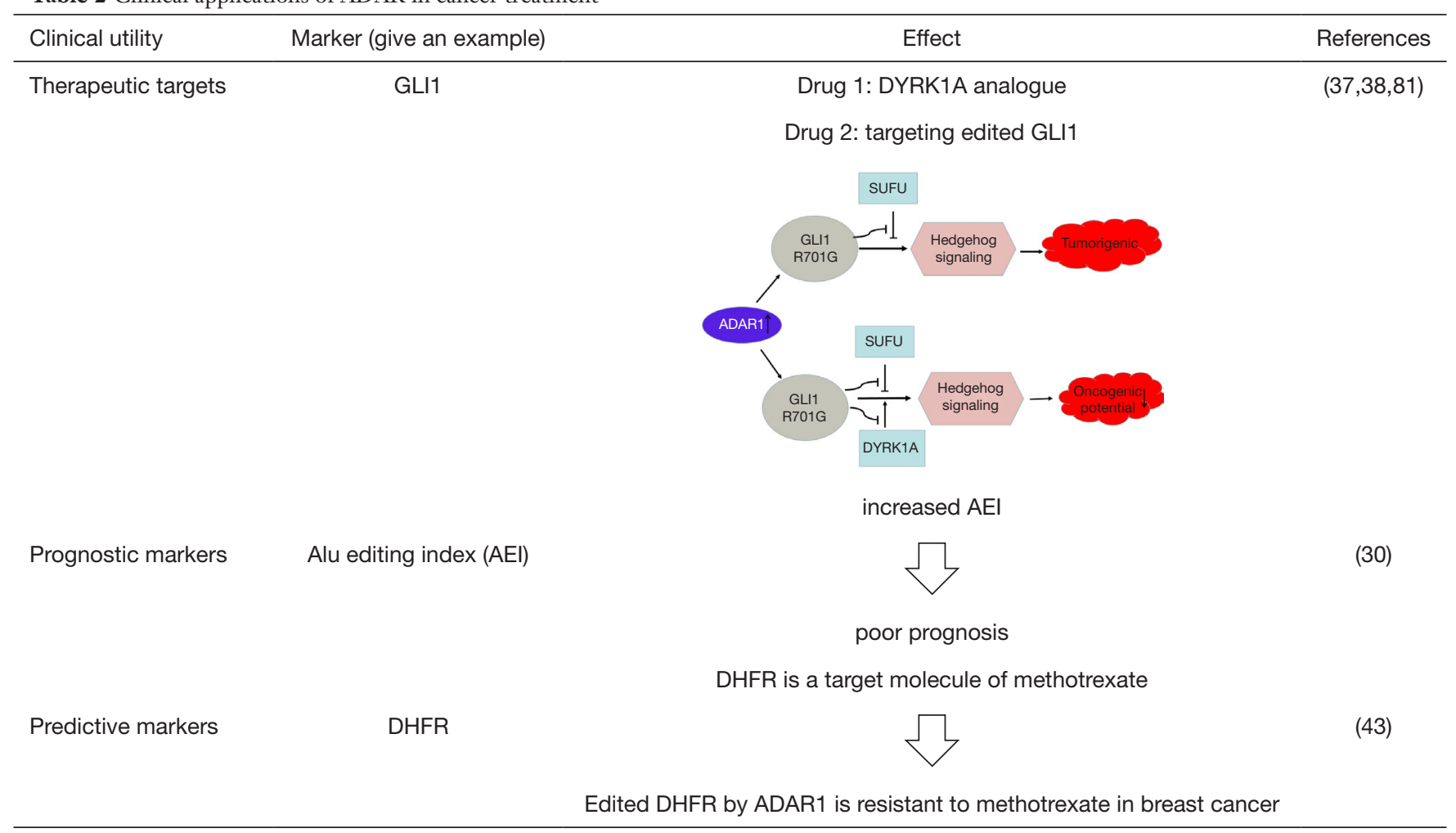

DYRK1A, dual specificity tyrosine-phosphorylation-regulated kinase 1A; SUFU, suppressor of fused.

mediates dynamic actin cytoskeletal recombination, thus promoting invasive potential. Edited RHOQ is related to ascending relapse rate, which is higher while connected with mutant KRAS (G12D). RHOQ distorted editing is also common in GC, lung cancer and HCC (29).

Overall, these results reflect the mechanisms of ADAR in tumors and suggest potential large-scale clinical implications.

\section{Clinical utility}

Aberrant ADAR-mediated editing provides an underexplored mechanism for altering proteins and regulating dsRNA sequences which can act as driving factors and suggest biomarkers and cancer treatment targets. Monitoring ADAR expression levels or RNA editing activity is a useful early biomarker for detecting cancer even before clinical symptoms become apparent (Table 2).

\section{Therapeutic targets}

ADAR1 is a promising therapeutic target because loss of activity leads to cell inherent fatality and IFN-I induction. ADAR1 repression directly kills cancer cells expressing high levels of ISGs through protein kinase R (PKR) activity (112). ADAR1 repression may enlarge IFN-I response by triggering IFN- $\beta$ production by cells in the tumor microenvironment. These findings suggest that ADAR1 is a potential therapeutic target in cancer. Furthermore, ADAR1 inhibitors can synergize with cancer immunotherapy by stimulating cytotoxic $\mathrm{T}$ cells and natural killer cells (112). Similarly, ADAR2 is a promising target because it regulates multiple miRNAs and cellular pathways simultaneously in cancer cells. Compounds capable of regulating the expression of ADAR2 in glioblastoma could be developed as anti-cancer therapy.

The targets of ADAR are also therapeutic direction that can be explored. For example, FAK is a relatively mature biomarker in advanced solid malignancies. FAK inhibitors like VS-6063 (defactinib), GSK2256098 and VS-4718 are improved anticancer immunotherapy. (Content derives from https://clinicaltrials.gov).

In addition, molecular tools can be developed to selectively inhibit RNA editing. Site-selective editing 
inhibiting agent may treat cancers whose site is overedited (113). In cancer cells with ADAR2 downregulation, SNAPtag technology can target specific RNA editing events, which may inhibit the development of cancer (114). The synthesis of RNA-guided editing enzymes for targetspecific RNA editing is another potential direction. It is possible to target cancer-related genes and appropriately restore protein function through the CRISPR-Cas genome editing system (22).

\section{Prognostic markers}

The editing level of many RNA editing sites is related to survival time of patients, indicating that the level of editing at specific RNA sites can be used as a prognostic marker $(30,47,86)$. For example, the Alu editing index (AEI) refers to weighted man editing level of all expressed Alu sequences. High index is related to poor prognosis of cancers (30). In addition, miR-122 is a liver-enriched miRNA. 'Serum miR-122 may act as a real-time monitor marker of chemotherapy induced liver injury.' (Content derives from https://clinicaltrials.gov).

\section{Predictive markers}

Particular ADAR editing events can influence reactions to cancer treatment, indicating that they are predictive biomarkers. For instance, edited COG3 and GRIA2 can improve the susceptibility to MEK inhibiting agents (86). In addition, hepatic and circulating miR-22 1 and miR222 is of clinical meaning in HCC. (Content derives from https://clinicaltrials.gov) If assessment demonstrates that circulating miRNAs are relevant and reliable in diagnosis and follow-up of HCC, then treatments for the miRNAs and associated pathways may be used clinically rather than the necessary for pathology of liver biopsies.

In principle, regulating ADAR expression is a promising direction in the treatment of cancer. However, because many other diseases are related to altered A-to-I editing levels, reversing cancer by regulating RNA editing levels may have unintended consequences.

\section{Conclusions}

In recent years, high-throughput sequencing and TCGA have detected significant changes in ADAR-mediated editing in many cancers. RNA editing is the main biological function of ADARs. This review discussed current important ADAR-mediated editing events, related carcinogenic mechanism and the related clinical applications.

Taken together, research studies have revealed several issues that need to be addressed. The relationship among editing enzymes is complex, especially that between ADAR1 and ADAR2, which can cooperate or antagonize each other. For example, PODXL expression is controlled through rate between PODXL edited by ADAR1 and ADAR2. ADAR1 p150 and p110 show functional differences in cancer, however, studies often do not clearly distinguish the degree of involvement of each isoform. In addition, there are few studies addressing the role of ADAR3 in cancer. The mechanism by which ADARs activate or regulate oncogenic signaling remains unclear. The same editing event may result in a completely different function or phenotype, such as the aforementioned ADAR1-mediated GLI1 editing and ADAR2-mediated COPA editing. The extent to which RNA editing alterations affect protein modifications remains unclear. Some cancer-related editing sites lack distinct recognition of related editing enzymes, such as PTPN6 in AML and RHOQ in CRC. Furthermore, the interaction network between ADAR RNA editing and other tumorigenesis-related pathways and factors remains unclear.

In the future, potential biomarkers, cancer treatment targets, and molecular tools for regulation of RNA editing need to be identified and characterized for clinical application. ADAR RNA editing is also important for the accuracy and reference value of patient prognosis. Specific RNA editing events can selectively influence the response to cancer treatment. The application of RNA editing to improve the sensitivity to drugs and reduce the incidence of drug resistance is a key issue to be studied. Possible future directions in cancer treatment include the development of drugs targeting ADAR1, ADAR2, and editing sites; and exploring whether they can synergize with existing targeted drugs, immunotherapy, and other cancer treatments. Further elucidation of the mechanisms underlying ADAR functions will provide important insight for the development of anticancer treatments.

\section{Acknowledgments}

Funding: This work was supported by grants from the National Natural Science Foundation of China (81572262), the Jiangsu Province's Key Provincial Talents Program (ZDRCA2016028), 333 high class Talented Man Project (BRA2016516) and the Natural Science Foundation 
of the Jiangsu Higher Education Institution of China (18KJB320006).

\section{Footnote}

Conflicts of Interest: The authors have no conflicts of interest to declare.

Ethical Statement: The authors are accountable for all aspects of the work in ensuring that questions related to the accuracy or integrity of any part of the work are appropriately investigated and resolved.

\section{References}

1. Sharma S, Kelly TK, Jones PA. Epigenetics in cancer. Carcinogenesis 2010;31:27-36.

2. Federica Galeano ST, Franco Locatelli, Angela Gallo. A-to-I RNA editing: The "ADAR" side of human cancer. Seminars in Cell \& Developmental Biology 2012;23:244-50.

3. Wang C, Zou J, Ma X, et al. Mechanisms and implications of ADAR-mediated RNA editing in cancer. Cancer Lett 2017;411:27-34.

4. Bass BL, Weintraub $\mathrm{H}$. A developmentally regulated activity that unwinds RNA duplexes. Cell 1987;48:607-13.

5. Jin Y, Zhang W, Li Q. Origins and evolution of ADARmediated RNA editing. IUBMB Life 2009;61:572-8.

6. Qi L, Song Y, Chan THM, et al. An RNA editing/ dsRNA binding-independent gene regulatory mechanism of ADARs and its clinical implication in cancer. Nucleic Acids Res 2017;45:10436-51.

7. Rahman $\mathrm{R}, \mathrm{Xu} \mathrm{W}$, Jin $\mathrm{H}$, et al. Identification of RNAbinding protein targets with HyperTRIBE. Nat Protoc 2018;13:1829-49.

8. Eckmann CR, Neunteufl A, Pfaffstetter L, et al. The human but not the Xenopus RNA-editing enzyme ADAR1 has an atypical nuclear localization signal and displays the characteristics of a shuttling protein. Mol Biol Cell 2001;12:1911-24.

9. Sansam CL, Wells KS, Emeson RB. Modulation of RNA editing by functional nucleolar sequestration of ADAR2. Proc Natl Acad Sci U S A 2003;100:14018-23.

10. Bazak L, Haviv A, Barak M, et al. A-to-I RNA editing occurs at over a hundred million genomic sites, located in a majority of human genes. Genome Res 2014;24:365-76.

11. Sinigaglia K, Wiatrek D, Khan A, et al. ADAR RNA editing in innate immune response phasing, in circadian clocks and in sleep. Biochim Biophys Acta Gene Regul
Mech 2019;1862:356-69.

12. Peng $Z$, Cheng $Y$, Tan BC, et al. Comprehensive analysis of RNA-Seq data reveals extensive RNA editing in a human transcriptome. Nat Biotechnol 2012;30:253-60.

13. Fumagalli D, Gacquer D, Rothe F, et al. Principles Governing A-to-I RNA Editing in the Breast Cancer Transcriptome. Cell Rep 2015;13:277-89.

14. Rajendren S, Manning AC, Al-Awadi H, et al. A proteinprotein interaction underlies the molecular basis for substrate recognition by an adenosine-to-inosine RNAediting enzyme. Nucleic Acids Res 2018;46:9647-59.

15. Wang Q, Khillan J, Gadue P, et al. Requirement of the RNA editing deaminase ADAR1 gene for embryonic erythropoiesis. Science 2000;290:1765-8.

16. Hartner JC, Schmittwolf C, Kispert A, et al. Liver disintegration in the mouse embryo caused by deficiency in the RNA-editing enzyme ADAR1. J Biol Chem 2004;279:4894-902.

17. Wang Q, Miyakoda M, Yang W, et al. Stress-induced apoptosis associated with null mutation of ADAR1 RNA editing deaminase gene. J Biol Chem 2004;279:4952-61.

18. Hartner JC, Walkley CR, Lu J, et al. ADAR1 is essential for the maintenance of hematopoiesis and suppression of interferon signaling. Nat Immunol 2009;10:109-15.

19. Fritzell K, Xu LD, Otrocka M, et al. Sensitive ADAR editing reporter in cancer cells enables high-throughput screening of small molecule libraries. Nucleic Acids Res 2019;47:e22.

20. Mannion NM, Greenwood SM, Young R, et al. The RNAediting enzyme ADAR1 controls innate immune responses to RNA. Cell Rep 2014;9:1482-94.

21. Roth SH, Danan-Gotthold M, Ben-Izhak M, et al. Increased RNA Editing May Provide a Source for Autoantigens in Systemic Lupus Erythematosus. Cell Rep 2018;23:50-7.

22. Kung CP, Maggi LB, Weber JD. The Role of RNA Editing in Cancer Development and Metabolic Disorders. Front Endocrinol (Lausanne) 2018;9:762.

23. Tan MH, Li Q, Shanmugam R, et al. Dynamic landscape and regulation of RNA editing in mammals. Nature 2017;550:249-54.

24. Clerzius G, Gelinas JF, Daher A, et al. ADAR1 interacts with PKR during human immunodeficiency virus infection of lymphocytes and contributes to viral replication. J Virol 2009;83:10119-28.

25. Heale BS, Keegan LP, McGurk L, et al. Editing independent effects of ADARs on the miRNA/siRNA pathways. EMBO J 2009;28:3145-56. 
26. Wang IX, So E, Devlin JL, et al. ADAR regulates RNA editing, transcript stability, and gene expression. Cell Rep 2013;5:849-60.

27. Picardi E, D'Erchia AM, Lo Giudice C, et al. REDIportal: a comprehensive database of A-to-I RNA editing events in humans. Nucleic Acids Res 2017;45:D750-D757.

28. Hong H, An O, Chan THM, et al. Bidirectional regulation of adenosine-to-inosine (A-to-I) RNA editing by DEAH box helicase 9 (DHX9) in cancer. Nucleic Acids Res 2018;46:7953-69.

29. Han SW, Kim HP, Shin JY, et al. RNA editing in RHOQ promotes invasion potential in colorectal cancer. J Exp Med 2014;211:613-21.

30. Paz-Yaacov N, Bazak L, Buchumenski I, et al. Elevated RNA Editing Activity Is a Major Contributor to Transcriptomic Diversity in Tumors. Cell Rep 2015;13:267-76.

31. Paz N, Levanon EY, Amariglio N, et al. Altered adenosineto-inosine RNA editing in human cancer. Genome Res 2007;17:1586-95.

32. Chen L, Li Y, Lin CH, et al. Recoding RNA editing of AZIN1 predisposes to hepatocellular carcinoma. Nat Med 2013;19:209-16.

33. Shigeyasu K, Okugawa Y, Toden S, et al. AZIN1 RNA editing confers cancer stemness and enhances oncogenic potential in colorectal cancer. JCI Insight 2018. doi: 10.1172/jci.insight.99976.

34. Qin YR, Qiao JJ, Chan TH, et al. Adenosine-to-Inosine RNA Editing Mediated by ADARs in Esophageal Squamous Cell Carcinoma. Cancer Res 2014;74:840-51.

35. Hu X, Chen J, Shi X, et al. RNA editing of AZIN1 induces the malignant progression of non-small-cell lung cancers. Tumour Biol 2017;39:1010428317700001.

36. Olsen RR, Zetter BR. Evidence of a role for antizyme and antizyme inhibitor as regulators of human cancer. Mol Cancer Res 2011;9:1285-93.

37. Shimokawa T, Rahman MF, Tostar U, et al. RNA editing of the GLI1 transcription factor modulates the output of Hedgehog signaling. RNA Biol 2013;10:321-33.

38. Lazzari E, Mondala PK, Santos ND, et al. Alu-dependent RNA editing of GLI1 promotes malignant regeneration in multiple myeloma. Nat Commun 2017;8:1922.

39. Teoh PJ, An O, Chung TH, et al. Aberrant hyperediting of the myeloma transcriptome by ADAR 1 confers oncogenicity and is a marker of poor prognosis. Blood 2018;132:1304-17.

40. Chen W, He W, Cai H, et al. A-to-I RNA editing of BLCAP lost the inhibition to STAT3 activation in cervical cancer. Oncotarget 2017;8:39417-29.

41. Hu X, Wan S, Ou Y, et al. RNA over-editing of BLCAP contributes to hepatocarcinogenesis identified by wholegenome and transcriptome sequencing. Cancer Lett 2015;357:510-9.

42. Galeano F, Leroy A, Rossetti C, et al. Human BLCAP transcript: new editing events in normal and cancerous tissues. Int J Cancer 2010;127:127-37.

43. Nakano M, Fukami T, Gotoh S, et al. A-to-I RNA Editing Up-regulates Human Dihydrofolate Reductase in Breast Cancer. J Biol Chem 2017;292:4873-84.

44. Amin EM, Liu Y, Deng S, et al. The RNA-editing enzyme ADAR promotes lung adenocarcinoma migration and invasion by stabilizing FAK. Sci Signal 2017. doi: 10.1126/ scisignal.aah3941.

45. Zipeto MA, Court AC, Sadarangani A, et al. ADAR1 Activation Drives Leukemia Stem Cell Self-Renewal by Impairing Let-7 Biogenesis. Cell Stem Cell 2016;19:177-91.

46. Jiang Q, Crews LA, Barrett CL, et al. ADAR1 promotes malignant progenitor reprogramming in chronic myeloid leukemia. Proc Natl Acad Sci U S A 2013;110:1041-6.

47. Wang Y, Xu X, Yu S, et al. Systematic characterization of A-to-I RNA editing hotspots in microRNAs across human cancers. Genome Res 2017;27:1112-25.

48. Salameh A, Lee AK, Cardo-Vila M, et al. PRUNE2 is a human prostate cancer suppressor regulated by the intronic long noncoding RNA PCA3. Proc Natl Acad Sci U S A 2015;112:8403-8.

49. Shoshan E, Mobley AK, Braeuer RR, et al. Reduced adenosine-to-inosine miR-455-5p editing promotes melanoma growth and metastasis. Nat Cell Biol 2015;17:311-21.

50. Velazquez-Torres G, Shoshan E, Ivan C, et al. A-to-I miR-378a-3p editing can prevent melanoma progression via regulation of PARVA expression. Nat Commun 2018;9:461.

51. Gumireddy K, Li A, Kossenkov AV, et al. The mRNAedited form of GABRA3 suppresses GABRA3-mediated Akt activation and breast cancer metastasis. Nat Commun 2016;7:10715.

52. Zhang M, Fritsche J, Roszik J, et al. RNA editing derived epitopes function as cancer antigens to elicit immune responses. Nat Commun 2018;9:3919.

53. Rodier G, Coulombe P, Tanguay PL, et al. Phosphorylation of Skp2 regulated by CDK2 and Cdc14B protects it from degradation by APC(Cdh1) in G1 phase. EMBO J 2008;27:679-91.

54. Galeano F, Rossetti C, Tomaselli S, et al. ADAR2- 
editing activity inhibits glioblastoma growth through the modulation of the CDC14B/Skp2/p21/p27 axis. Oncogene 2013;32:998-1009.

55. Cenci C, Barzotti R, Galeano F, et al. Down-regulation of RNA editing in pediatric astrocytomas: ADAR2 editing activity inhibits cell migration and proliferation. J Biol Chem 2008;283:7251-60.

56. Ishiuchi S, Tsuzuki K, Yoshida Y, et al. Blockage of $\mathrm{Ca}(2+)$ permeable AMPA receptors suppresses migration and induces apoptosis in human glioblastoma cells. Nat Med 2002;8:971-8.

57. Maas S, Patt S, Schrey M, et al. Underediting of glutamate receptor GluR-B mRNA in malignant gliomas. Proc Natl Acad Sci U S A 2001;98:14687-92.

58. Ishiuchi S, Yoshida Y, Sugawara K, et al. Ca2+-permeable AMPA receptors regulate growth of human glioblastoma via Akt activation. J Neurosci 2007;27:7987-8001.

59. Oakes E, Anderson A, Cohen-Gadol A, et al. Adenosine Deaminase That Acts on RNA 3 (ADAR3) Binding to Glutamate Receptor Subunit B Pre-mRNA Inhibits RNA Editing in Glioblastoma. J Biol Chem 2017;292:4326-35.

60. Tomaselli S, Galeano F, Alon S, et al. Modulation of microRNA editing, expression and processing by ADAR2 deaminase in glioblastoma. Genome Biology 2015;16:5.

61. Asangani IA, Rasheed SA, Nikolova DA, et al. MicroRNA-21 (miR-21) post-transcriptionally downregulates tumor suppressor Pdcd4 and stimulates invasion, intravasation and metastasis in colorectal cancer. Oncogene 2008;27:2128-36.

62. Choudhury Y, Tay FC, Lam DH, et al. Attenuated adenosine-to-inosine editing of microRNA-376a* promotes invasiveness of glioblastoma cells. J Clin Invest 2012;122:4059-76.

63. Cesarini V, Silvestris DA, Tassinari V, et al. ADAR2/miR589-3p axis controls glioblastoma cell migration/invasion. Nucleic Acids Res 2018;46:2045-59.

64. Chan TH, Lin CH, Qi L, et al. A disrupted RNA editing balance mediated by ADARs (Adenosine DeAminases that act on RNA) in human hepatocellular carcinoma. Gut 2014;63:832-43.

65. Shelton PM, Duran A, Nakanishi Y, et al. The Secretion of miR-200s by a PKCzeta/ADAR2 Signaling Axis Promotes Liver Metastasis in Colorectal Cancer. Cell Rep 2018;23:1178-91.

66. Liu WH, Chen CH, Yeh KH, et al. ADAR2-mediated editing of miR-214 and miR-122 precursor and antisense RNA transcripts in liver cancers. PLoS One 2013;8:e81922.

67. Shih TC, Tien YJ, Wen CJ, et al. MicroRNA-214 downregulation contributes to tumor angiogenesis by inducing secretion of the hepatoma-derived growth factor in human hepatoma. J Hepatol 2012;57:584-91.

68. Li B, Han Q, Zhu Y, et al. Down-regulation of miR-214 contributes to intrahepatic cholangiocarcinoma metastasis by targeting Twist. Febs j 2012;279:2393-8.

69. Girard M, Jacquemin E, Munnich A, et al. miR-122, a paradigm for the role of microRNAs in the liver. J Hepatol 2008;48:648-56.

70. Chen YB, Liao XY, Zhang JB, et al. ADAR2 functions as a tumor suppressor via editing IGFBP7 in esophageal squamous cell carcinoma. Int J Oncol 2017;50:622-30.

71. Fu L, Qin YR, Ming XY, et al. RNA editing of SLC22A3 drives early tumor invasion and metastasis in familial esophageal cancer. Proc Natl Acad Sci U S A 2017;114:E4631-E4640.

72. Wang F, Wang XS, Yang GH, et al. miR-29a and miR-142$3 p$ downregulation and diagnostic implication in human acute myeloid leukemia. Mol Biol Rep 2012;39:2713-22.

73. Chen YT, Chang IY, Liu H, et al. Tumor-associated intronic editing of HNRPLL generates a novel splicing variant linked to cell proliferation. J Biol Chem 2018;293:10158-71.

74. Chan TH, Qamra A, Tan KT, et al. ADAR-Mediated RNA Editing Predicts Progression and Prognosis of Gastric Cancer. Gastroenterology 2016;151:637-650.e10.

75. Sizemore S, Cicek M, Sizemore N, et al. Podocalyxin increases the aggressive phenotype of breast and prostate cancer cells in vitro through its interaction with ezrin. Cancer Res 2007;67:6183-91.

76. Galore-Haskel G, Nemlich Y, Greenberg E, et al. A novel immune resistance mechanism of melanoma cells controlled by the ADAR1 enzyme. Oncotarget 2015;6:28999-9015.

77. Silvestris DA, Picardi E, Cesarini V, et al. Dynamic inosinome profiles reveal novel patient stratification and gender-specific differences in glioblastoma. Genome Biology 2019;20:33.

78. Beghini A, Ripamonti CB, Peterlongo P, et al. RNA hyperediting and alternative splicing of hematopoietic cell phosphatase (PTPN6) gene in acute myeloid leukemia. Hum Mol Genet 2000;9:2297-304.

79. Porath HT, Carmi S, Levanon EY. A genome-wide map of hyper-edited RNA reveals numerous new sites. Nat Commun 2014;5:4726.

80. Eifler T, Pokharel S, Beal PA. RNA-Seq analysis identifies 
a novel set of editing substrates for human ADAR2 present in Saccharomyces cerevisiae. Biochemistry 2013;52:7857-69.

81. Kasper M, Regl G, Frischauf AM, et al. GLI transcription factors: mediators of oncogenic Hedgehog signalling. Eur J Cancer 2006;42:437-45.

82. Xiao C, Ogle SA, Schumacher MA, et al. Hedgehog signaling regulates E-cadherin expression for the maintenance of the actin cytoskeleton and tight junctions. Am J Physiol Gastrointest Liver Physiol 2010;299:G1252-65.

83. Gromova I, Gromov P, Celis JE. bc10: A novel human bladder cancer-associated protein with a conserved genomic structure downregulated in invasive cancer. Int J Cancer 2002;98:539-46.

84. Yao J, Duan L, Fan M, et al. Overexpression of BLCAP induces $\mathrm{S}$ phase arrest and apoptosis independent of $\mathrm{p} 53$ and NF-kappaB in human tongue carcinoma: BLCAP overexpression induces $\mathrm{S}$ phase arrest and apoptosis. Mol Cell Biochem 2007;297:81-92.

85. Fan DG, Zhao F, Ding Y, et al. BLCAP induces apoptosis in human Ewing's sarcoma cells. Exp Biol Med (Maywood) 2011;236:1030-5.

86. Han L, Diao L, Yu S, et al. The Genomic Landscape and Clinical Relevance of A-to-I RNA Editing in Human Cancers. Cancer Cell 2015;28:515-28.

87. Sagredo EA, Blanco A, Sagredo AI, et al. ADAR1mediated RNA-editing of 3'UTRs in breast cancer. Biol Res 2018;51:36.

88. Steinman RA, Yang Q, Gasparetto M, et al. Deletion of the RNA-editing enzyme ADAR1 causes regression of established chronic myelogenous leukemia in mice. Int J Cancer 2013;132:1741-50.

89. Yang W, Chendrimada TP, Wang Q, et al. Modulation of microRNA processing and expression through RNA editing by ADAR deaminases. Nat Struct Mol Biol 2006;13:13-21.

90. Bussemakers MJ, van Bokhoven A, Verhaegh GW, et al. DD3: a new prostate-specific gene, highly overexpressed in prostate cancer. Cancer Res 1999;59:5975-9.

91. Nemlich Y, Greenberg E, Ortenberg R, et al. MicroRNAmediated loss of ADAR1 in metastatic melanoma promotes tumor growth. J Clin Invest 2013;123:2703-18.

92. Ohlson J, Pedersen JS, Haussler D, et al. Editing modifies the GABA(A) receptor subunit alpha3. Rna 2007;13:698-703.

93. Neman J, Termini J, Wilczynski S, et al. Human breast cancer metastases to the brain display GABAergic properties in the neural niche. Proc Natl Acad Sci U S A 2014;111:984-9.

94. Daniel C, Wahlstedt H, Ohlson J, et al. Adenosine-toinosine RNA editing affects trafficking of the gammaaminobutyric acid type A (GABA(A)) receptor. J Biol Chem 2011;286:2031-40.

95. Wahlstedt H, Daniel C, Enstero M, et al. Large-scale mRNA sequencing determines global regulation of RNA editing during brain development. Genome Res 2009;19:978-86.

96. Coqueret O. New roles for p21 and p27 cell-cycle inhibitors: a function for each cell compartment? Trends Cell Biol 2003;13:65-70.

97. Abukhdeir AM, Park BH. P21 and p27: roles in carcinogenesis and drug resistance. Expert Rev Mol Med 2008;10:e19.

98. Kitagawa K, Kotake Y, Kitagawa M. Ubiquitin-mediated control of oncogene and tumor suppressor gene products. Cancer Sci 2009; 100:1374-81.

99. Fritzell K, Xu LD, Lagergren J, et al. ADARs and editing: The role of A-to-I RNA modification in cancer progression. Semin Cell Dev Biol 2018;79:123-30.

100. Ota H, Sakurai M, Gupta R, et al. ADAR1 forms a complex with Dicer to promote microRNA processing and RNA-induced gene silencing. Cell 2013;153:575-89.

101.Alon S, Mor E, Vigneault F, et al. Systematic identification of edited microRNAs in the human brain. Genome Res 2012;22:1533-40.

102. Nishimura N, Van Huyen Pham T, Hartomo TB, et al. Rab15 expression correlates with retinoic acid-induced differentiation of neuroblastoma cells. Oncol Rep 2011;26:145-51.

103.Strick DJ, Elferink LA. Rab15 effector protein: a novel protein for receptor recycling from the endocytic recycling compartment. Mol Biol Cell 2005;16:5699-709.

104. Gommans WM, Tatalias NE, Sie CP, et al. Screening of human SNP database identifies recoding sites of A-to-I RNA editing. Rna 2008;14:2074-85.

105.Levanon EY, Hallegger M, Kinar Y, et al. Evolutionarily conserved human targets of adenosine to inosine RNA editing. Nucleic Acids Res 2005;33:1162-8.

106. Chen CZ, Li L, Lodish HF, et al. MicroRNAs modulate hematopoietic lineage differentiation. Science 2004;303:83-6.

107. Bahn JH, Ahn J, Lin X, et al. Genomic analysis of ADAR1 binding and its involvement in multiple RNA processing pathways. Nat Commun 2015;6:6355.

108. Bachmann MF, McKall-Faienza K, Schmits R, et al. 
Distinct roles for LFA-1 and CD28 during activation of naive $T$ cells: adhesion versus costimulation. Immunity 1997;7:549-57.

109. Jenkins MR, Griffiths GM. The synapse and cytolytic machinery of cytotoxic T cells. Curr Opin Immunol 2010;22:308-13.

110.Dong Q, Siminovitch KA, Fialkow L, et al. Negative regulation of myeloid cell proliferation and function by the SH2 domain-containing tyrosine phosphatase-1. J Immunol 1999;162:3220-30.

111. Gauffin F, Diffner E, Gustafsson B, et al. Expression of PTEN and SHP1, investigated from tissue microarrays in

Cite this article as: Zhang $\mathrm{Y}$, Qian $\mathrm{H}, \mathrm{Xu}$ J, Gao W. ADAR, the carcinogenesis mechanisms of ADAR and related clinical applications. Ann Transl Med 2019;7(22):686. doi: 10.21037/ atm.2019.11.06 pediatric acute lymphoblastic, leukemia. Pediatr Hematol Oncol 2009;26:48-56.

112. Gannon HS, Zou T, Kiessling MK, et al. Identification of ADAR1 adenosine deaminase dependency in a subset of cancer cells. Nat Commun 2018;9:5450.

113. Nakano M, Nakajima M. Significance of A-to-I RNA editing of transcripts modulating pharmacokinetics and pharmacodynamics. Pharmacol Ther 2018;181:13-21.

114. Hanswillemenke A, Kuzdere T, Vogel P, et al. SiteDirected RNA Editing in Vivo Can Be Triggered by the Light-Driven Assembly of an Artificial Riboprotein. J Am Chem Soc 2015;137:15875-81. 